\title{
MEDIA DAY: INCLUSÃO POR MEIO DO ENSINO
}

\author{
R. S. Frota ${ }^{1}$; V. F. Macedo ${ }^{2}$ \& G. C. Pereira ${ }^{3}$
}

${ }^{1}$ Bolsista e graduanda pela Universidade Federal do Ceará (UFC). E-mail: raissadossantosfrota@gmail.com; ${ }^{2}$ Voluntária e graduanda pela Universidade Federal do Ceará (UFC). E-mail: vitoriafacundo@ hotmail.com; ${ }^{3}$ Coordenadora de ação extensionista de mesmo nome do artigo. E-mail: georgia@ virtual.ufc.br

Artigo submetido em setembro/2017

\section{RESUMO}

O Media Day é um projeto de extensão itinerante e tem o objetivo de fomentar os conhecimentos e habilidades dos seus participantes, proporcionando contato direto e prático com as áreas de estudo do Curso de Sistemas e Mídias Digitais da Universidade Federal do Ceará, divulgando em diversas cidades do estado do Ceará os trabalhos desenvolvidos no curso e estimulando o interesse pela Universidade. O projeto tem como metodologia a preparação e a realização de oficinas durante um dia nas escolas públicas, promovendo a inclusão digital e a formação tanto dos participantes quanto dos alunos do curso. Realizado em algumas cidades do estado do Ceará, já contou com um público de aproximadamente 3118 participantes até novembro de 2017, totalizando 11 (onze) edições do evento. Os impactos positivos do projeto permitem a sua ampliação para outras cidades e outros públicos, como a formação direta para professores futuramente.

PALAVRAS-CHAVE: Inclusão. Docência. Tecnologia.

\section{MEDIA DAY: INCLUSION BY TEACHING}

\begin{abstract}
Media Day is an itinerant and extension project aims to enhance the knowledge and skills of its participants, providing practical and direct contact with the areas of study of Systems and digital media course at the Federal University of Ceará, disseminating in several cities in the State of Ceará in the Northeast region of the works developed on the course and stimulating interest in the University. The project's methodology the preparation and conducting of workshops during a
\end{abstract}

KEYWORDS: Inclusion. Teaching. Technology.

\section{INTRODUÇÃO}

O Media Day é um projeto de extensão itinerante pelo estado do Ceará e tem o objetivo de fomentar os conhecimentos e habilidades dos seus participantes, proporcionando contato direto e prático com as áreas de estudo do curso de Sistemas e Mídias Digitais (SMD) da UFC. Além disso, também são divulgados os trabalhos desenvolvidos no curso e estimula-se o interesse pela universidade através de rodas de conversa. Cada edição consiste em um dia inteiro de atividades como oficinas, palestras, rodas de conversa, jogos digitais e analógicos, 
sessão de cinema e práticas esportivas, podendo variar de acordo com a estrutura da escola parceira.

O desenvolvimento dessas atividades possibilita múltiplas experiências tanto para os universitários que atuam no projeto, como para os participantes do evento. Essas experiências proporcionam para o público informações acerca do mundo universitário e também do âmbito tecnológico, tendo como consequência uma inclusão digital, uma vez que muitos dos participantes ainda têm pouco acesso a produtos tecnológicos e ao devido letramento para o seu uso de maneira eficiente e eficaz.

Quando a inclusão é pensada no projeto e posta em prática, ela não diz respeito apenas à apresentação das tecnologias estudadas no curso, mas também sobre a conscientização do indivíduo acerca das suas possibilidades para construir seus próprios conhecimentos a partir daquilo que está sendo apresentado. Partindo disso, os indivíduos participantes podem modificar suas realidades, empreender novas práticas e agregar facilidades aos seus contextos sociais, seja como um professor que quer melhorar sua metodologia em sala de aula, seja como um jovem estudante que quer propor soluções para os problemas da sua comunidade, ou ainda como uma senhora que quer aprender a utilizar o celular para aumentar suas vendas.

Os universitários voluntários do projeto também passam a ser incluídos nas práticas docentes ao serem estimulados a ministrar palestras e oficinas, experimentando mais uma das vertentes que o curso pode proporcionar, a docência. Esta, por sua vez, possibilita que o universitário possa ter mais um caminho a seguir e, consequentemente, auxiliar na diminuição do número de evasão ao estimular nos discentes um desejo de se aprofundarem nos temas e ações de suas graduações.

Dessa forma, a realização do Media Day se justifica ao proporcionar a inclusão de todos aqueles que o realizam e participam, estimulando a autonomia, o protagonismo, a busca pelo conhecimento e a transformação do indivíduo e do meio em que vive através desse conhecimento. Essas características se tornam muito importantes nos dias atuais, à medida em que se faz necessária a participação ativa dos indivíduos para mudar suas realidades. Há ainda a possibilidade de explorar e alcançar novas oportunidades que podem ser aumentadas com esse acesso ao conhecimento e à tecnologia.

\section{INCLUSÃO DIGITAL}


Apesar de a sociedade ser considerada e caracterizada como globalizada e com informações e tecnologias totalmente acessíveis, Bonilla e Pretto (2011) discutem que ainda há muitos lugares em que esse acesso não existe.

De acordo com a PNAD 2010, relativa aos dados de 2009, apenas 35\% dos 58,6 milhões de domicílios brasileiros (20,3 milhões) contavam com microcomputador e, destes, 16 milhões tinham acesso à internet. Ou seja, mais de 4 milhões de domicílios contavam com computador, mas não estavam conectados à internet por falta de infraestrutura ou pela incapacidade da família de pagar pelo serviço (BONILLA; PRETTO, 2011).

Essa parcela da população além de ser excluída digitalmente, também pode ser considerada excluída socialmente, partindo-se do ponto de que a sociedade tem se tornado cada vez mais informatizada e digitalizada, e que aqueles indivíduos que não se encaixam nesse modelo de desenvolvimento têm sido empurrados cada vez mais para as margens.

Para Célio, Palmeira e Silva (2012), com tudo girando em torno da tecnologia, estar inserido digitalmente tornou-se uma condição fundamental para a existência de habitantes globais na interação com o mundo da informação e da comunicação.

Silveira (2003) vai além e coloca como sinônimo de comunicação essa inclusão digital dizendo que "hoje, o direito à comunicação é sinônimo de direito à comunicação mediada por computador. Portanto, trata-se de uma questão de cidadania". Cidadania esta que é responsabilizada por Martini (2005) às várias esferas de governo e também ao poder local. Cabe a eles proporcionar a oportunidades de incluir a população nos benefícios do mundo em rede, promover a cidadania digital e consolidar os direitos à cidadania.

Dessa forma, percebe-se que a inclusão digital não é uma questão simples, cuja solução passa apenas pelo aparato técnico - como projetos de compra de computadores para a população de baixa renda, ou ainda cursos com finalidades específicas de uso de softwares alheios a um contexto. Ter ou não acesso à infraestrutura tecnológica é apenas um dos fatores que influenciam a inclusão/exclusão digital, mas não é o único, nem o mais relevante (BONILLA, 2001).

Demo (2005) reafirma esse argumento e complementa dizendo que "a alfabetização digital significa habilidade imprescindível para ler a realidade e dela dar minimamente conta, para ganhar a vida e, acima de tudo, ser alguma coisa na vida. Em especial, é fundamental que o incluído controle sua inclusão".

O que Demo (2005) nomeia de alfabetização digital, Silva et al (2005), por sua vez, nomeia de letramento digital, embora suas definições não sejam divergentes. Para ambos, letramento digital seria a habilidade para construir sentido, capacidade para localizar, filtrar e 
avaliar criticamente informação eletrônica, estando essa em palavras, elementos pictóricos, sonoros ou qualquer outro.

Quando os excluídos passam a serem cidadãos digitais, estes por sua vez dão continuidade ao conhecimento adquirido, instrumentalizam esses conhecimentos e habilidades, pois são capazes de serem pessoas críticas através das tecnologias de informação e comunicação (TICs). Como diz Silva et al (2005), uma pessoa alfabetizada em informação seria aquela capaz de identificar a necessidade de informação, organizá-la e aplicá-la na prática, integrando-a a um corpo de conhecimentos existentes e usando-a na solução de problemas.

\section{LETRAMENTO DIGITAL ATRAVÉS DE OFICINAS E FORMAÇÃO ACADÊMICA}

De acordo com Bonilla e Pretto (2011), a apropriação e o uso das TICs constituem-se como necessidade, de tal forma que passamos a vivenciar, nos últimos anos, uma proliferação de cursos, projetos e programas que buscam oferecer acesso, treinamento e capacitação para o uso dessas tecnologias.

Contudo, não basta que essa capacitação trate apenas das ferramentas e dos softwares como foi mencionado por Bonilla (2001). A inclusão digital deve ser como um processo que começa no acesso e passa pela alfabetização digital, pelo ensino dos direitos e deveres da cidadania, pelo desenvolvimento das habilidades de pesquisa e produção na internet, e até pela programação (DIAS, 2011).

Essa produção e desenvolvimento de habilidades aliadas à alfabetização digital são pontos bem característicos do estilo de ensino com oficinas, que têm caráter prático, mas não só isso, como mostra Cavalcante e Silva (2015) quando colocam que "o objetivo das oficinas não é somente conferir capacitação técnica ao aluno, mas proporcionar-lhe uma oportunidade de reflexão crítica e ainda de expressão das suas subjetividades. "

Paviani e Fontana (2009) abordam o termo oficina como uma oportunidade de vivenciar situações concretas e significativas, baseada no tripé: sentir-pensar-agir, com objetivos pedagógicos. Não só os participantes das oficinas se beneficiam dessas vivências, mas o monitor/facilitador também acaba por aprender e agregar novas experiências. Como diz Freire (1996), "quem ensina aprende ao ensinar e quem aprende ensina ao aprender".

Nascimento (2007) também ilustra as oficinas como um momento de construção para todos os que estão envolvidos. 
Nesse sentido, as oficinas são espaços que apontam novas descobertas e caminhos, uma vez que consiste num processo em construção de todos os atores envolvidos, tornando-se espaços oportunos para a comunicação, para a contextualização, para o estabelecimento de vínculos, de reflexão, de mudanças, de construção coletiva de um saber (NASCIMENTO, 2007).

Freitas (2003) citado por Barreto (2004), trata o trabalho docente como prática docente ou prática reflexiva sustentando também expressões como atividades e tarefas docentes. Essas práticas não estão restritas à figura do professor, mas podem ser exercidas por outras pessoas que atuem no ensinar e aprender, ou as próprias práticas reflexivas. Aqui se encaixam oficineiros, monitores, projetos de iniciação à docência que vão experienciar essa relação de ensino e aprendizagem.

\section{MATERIAIS E MÉTODOS}

\subsection{CONTATO COM A ESCOLA}

Projeto de extensão da Universidade Federal do Ceará, o Media Day atua por meio de parceria com escolas públicas das cidades interessadas. O projeto ocorre nas escolas públicas das cidades, prioritariamente do interior, com as quais conseguimos fazer contato. As atividades geralmente são desenvolvidas aos finais de semanas, mas em ações na capital ou região metropolitana de Fortaleza algumas ações já aconteceram em outros dias.

Com os diretores ou coordenadores é conversado sobre as condições necessárias para que o evento aconteça tanto do ponto de vista pessoal quanto material. Assim, são colocadas em pauta a estrutura da escola (laboratórios, recursos multimídia, auditórios, acesso à internet etc.), transporte, alimentação e estadia de oficineiros (universitários voluntários) durante o período em que permanecerão na cidade (em geral, três dias). Feito esse levantamento, são planejadas oficinas e ações de acordo com a estrutura disponível na escola e o perfil de público informado pelos gestores, para que as atividades estejam compatíveis com a realidade do local. Ainda para o sucesso da ação são organizadas divulgações nas redes sociais e meios de acesso do público a ser beneficiado.

No primeiro dia, já se inicia a preparação na escola, pois é necessário conhecer a estrutura da escola e organizar espaços para as atividades, deixando tudo preparado para receber o público no dia seguinte. Durante o segundo dia, acontece o evento propriamente dito, em que ocorrem as oficinas, palestras e os momentos de interação que podem adentrar a noite. Nesse dia, no ato do credenciamento os participantes entregam alimentos não perecíveis, que são 
recolhidos e posteriormente doados a instituições ou a comunidades indicadas pelas escolas parceiras. No terceiro dia, a equipe de oficineiros e organização retornam a Fortaleza e fazem um balanço da ação, num processo de avaliação progressiva das atividades.

\subsection{PREPARAÇÃO DAS OFICINAS}

O trabalho no Media Day é ancorado no voluntariado e no estímulo ao protagonismo juvenil, em que jovens estudantes dialogam com outros para fomentar novos conhecimentos. Para a seleção dos oficineiros é criado um formulário online de inscrição de atividades, que ficam armazenados no banco de informações do projeto para edições futuras do evento. No formulário constam perguntas como: tipo de atividade a ser oferecida (oficina, palestra, batepapo etc.), duração necessária da atividade, materiais necessários e dados pessoais do candidato para que seja feito contato.

Em seguida, para a elaboração das oficinas é realizada uma análise da matriz curricular da escola (no caso de ocorrer em uma escola de ensino profissionalizante), para que haja uma fixação, ou seja, empregar de uma maneira suplementar os conteúdos que são ofertados na instituição de ensino juntamente aos conteúdos vistos no curso de Sistemas e Mídias Digitais. Visando não apenas a disseminação do curso do SMD, como também a aplicação desses conhecimentos midiáticos na contextualização do aluno, seja profissional ou acadêmica.

\subsection{PRODUÇÃO DE MATERIAL E DIVULGAÇÃO}

O processo de captação do público para o evento se dá por meio do contato direto da escola, a qual irá sediar a edição em sua cidade, com seus alunos e contando também com apoio da direção da escola para divulgação em outras instituições de ensino na cidade. Também se dá por meio das redes sociais do projeto (Facebook e Instagram), com a publicação da programação do evento discriminando as atividades que ocorrerão, convidando e alertando às novidades do evento. Além da indicação direta, que é realizada através do contato "boca a boca" feita pelos ex participantes do evento.

\subsection{O DIA DO EVENTO}


O evento inicia com o credenciamento dos inscritos e o recebimento dos alimentos doados, também havendo espaço para novas inscrições, essas feitas para controle de quantidade de público e envio de certificados, mas ainda assim aberto ao público. Em seguida, acontece a abertura, um momento comum a todos os participantes, onde são explicados os objetivos do projeto Media Day pelos bolsistas que o realizam. Logo após a abertura podem ocorrer palestras que discutem temas como a relação do curso de Sistemas e Mídias Digitais com o mercado de trabalho, dentre outros.

O período da manhã segue com diversos temas de oficinas com duração de três horas. A participação nas oficinas fica a critério do público de acordo com os temas de sua preferência. No evento já foram ofertadas oficinas que versaram sobre temas diversos tais quais audiovisual, design, narrativas, sistemas de informação, dentre outros. Há um intervalo para o almoço, cerca de duas horas, e no período da tarde as atividades são retomadas com mais uma sessão de oficinas. Concomitantemente são disponibilizados jogos digitais e analógicos, como atividades lúdicas em outros espaços da escola, uma vez que também faz parte do projeto a proposta de socialização dos jovens e apropriação do espaço escolar como ambiente de lazer e convivência. Para finalizar o evento, ocorre um bate-papo - que é considerado como essencial no evento com toda a equipe de oficineiros tirando dúvidas dos participantes acerca da universidade e compartilhando experiências.

Ao final de cada oficina é aplicado um questionário para obter o feedback das atividades desenvolvidas, o nível de satisfação, o quanto recomendaria o evento, se participaria de novo e sugestões. Junto a isso, são coletados os emails dos participantes para que os certificados de participação sejam enviados.

\section{RESULTADOS E DISCUSSÕES}

O Media Day foi realizado em algumas cidades do estado do Ceará, como: Sobral, Crateús, Aquiraz, Beberibe e Fortaleza, e já contou com um público de aproximadamente 3118 participantes até novembro de 2017, totalizando 11 (onze) edições do evento, e ainda uma edição especial dividida em 4 (quatro) encontros que consistiu em oficinas de Letramento Digital para um conjunto de mulheres nomeadas: "Mulheres de todas as cores que tem o brilho da lua”, que moram no Planalto Pici, no gráfico abaixo é possível ver a divisão do público em cada cidade. 
Gráfico I - Público alcançado por cidade

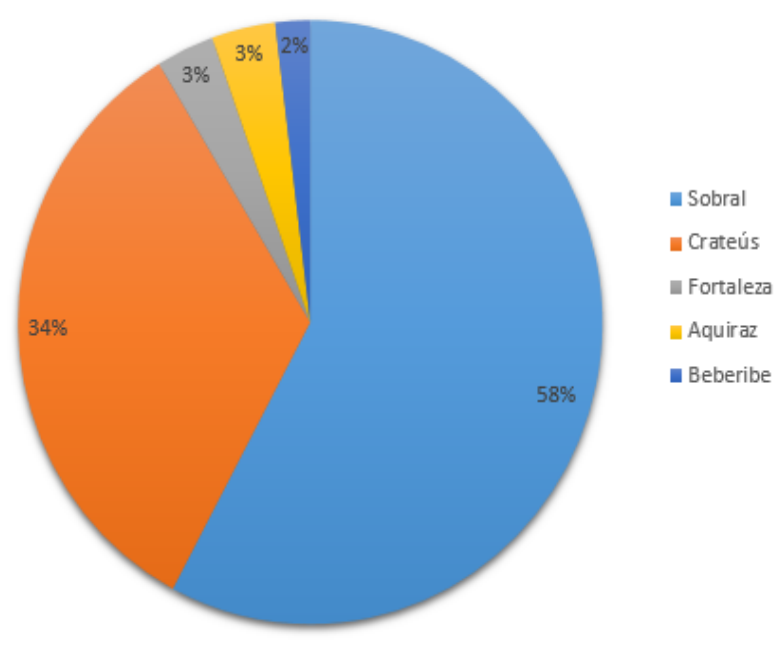

Dentre o público participante de todas as edições, há ainda uma predominância de participação do público do sexo masculino, correspondendo a 1309 pessoas, como é mostrado no gráfico II. Acerca desse dado, ainda, existem propostas para atrair mais participantes do sexo feminino para as atividades, incentivando seu ingresso na área das tecnologias aplicadas.

Gráfico II - Público alcançado por gênero

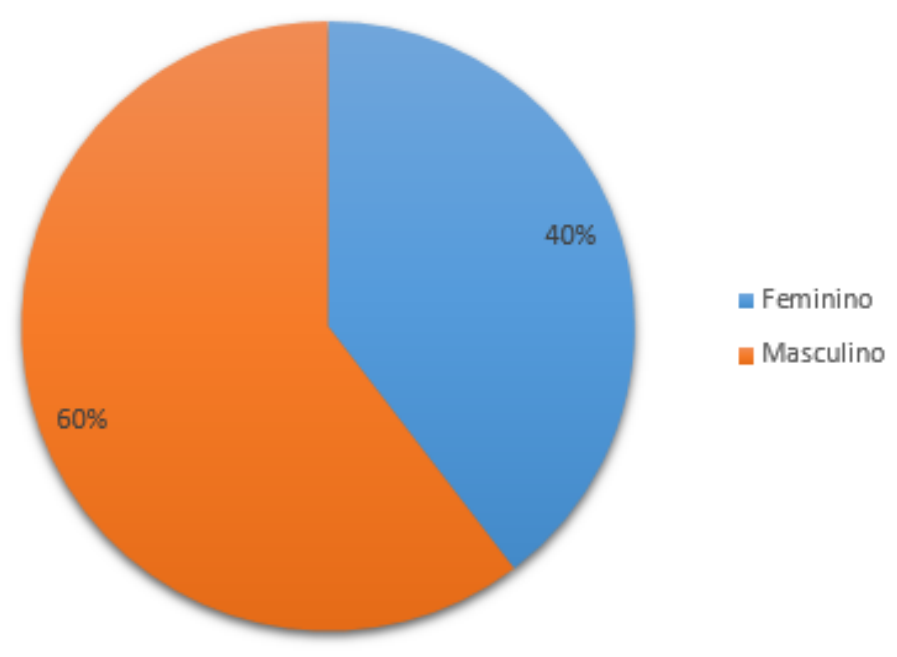

Sobre os meios de divulgação pelos quais os participantes souberam de todos os eventos do Media Day, as redes sociais figuram como principal meio de contato com o público, somando um total de $43 \%$ de participantes a terem sabido através desses meios. Outros meios de contato também podem ser observados no gráfico III. 
Gráfico III - Como o público ficou sabendo do evento

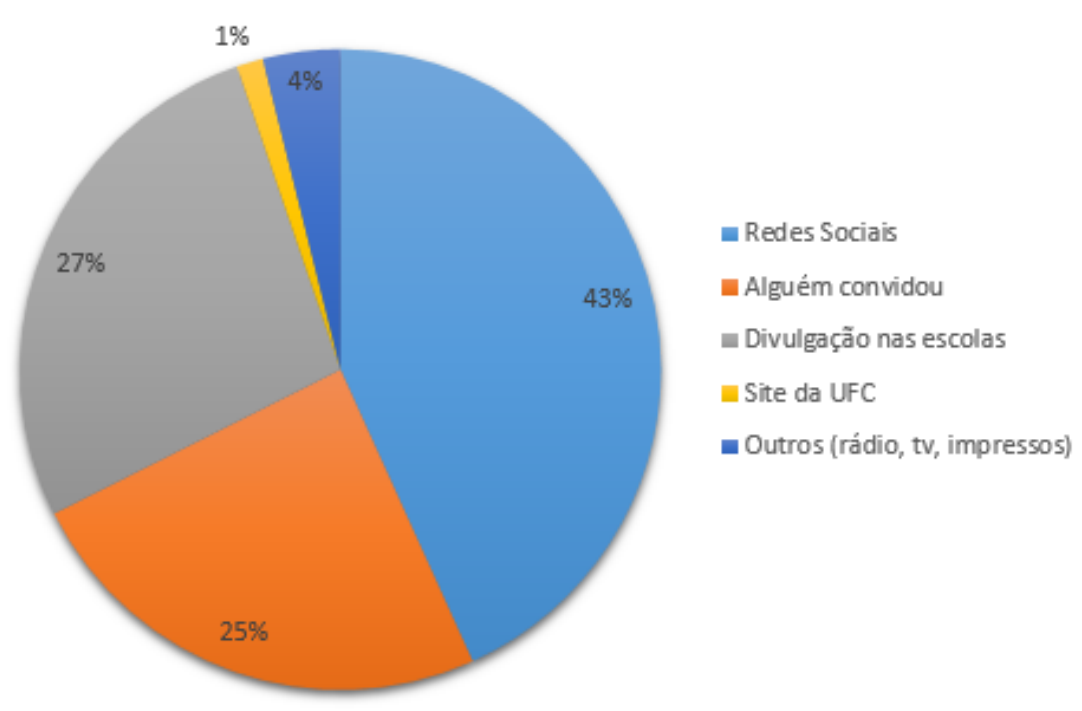

Com relação aos questionários, o nível de satisfação do evento é mostrado no gráfico IV, onde a maioria classificou como ótimo. A taxa de recomendação do evento teve alcance unânime de participantes, onde os 1795 respondentes (100\%) informaram que recomendariam o evento para amigos ou participariam novamente das oficinas.

Gráfico IV - Satisfação do público com o evento

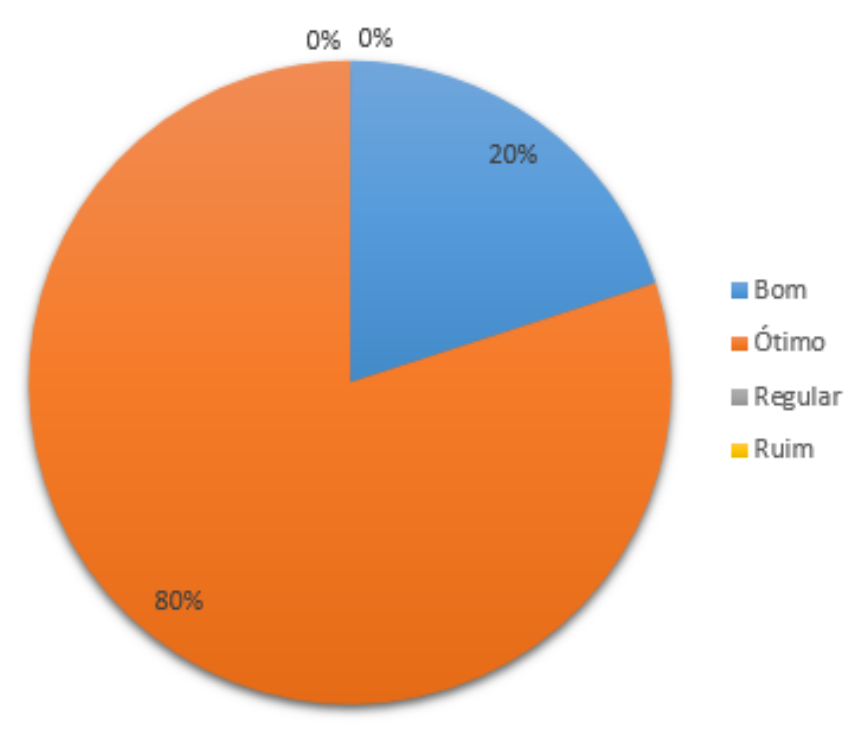

Durante as 9 edições realizadas até agosto de 2017, cada oficina foi ministrada por um oficineiro voluntário ou duplas. Até o momento foram ofertadas 112 oficinas, dentre as quais 42 foram originalmente pensadas para o projeto, sendo elas relacionadas a: desenvolvimento de jogos digitais e analógicos, editoração e manipulação de imagens, animação e modelagem, desenho, mídias sociais, design de interface e de experiência, edição de vídeo, tipografia, 
narrativas, programação mobile e web, fotografia, dentre outras.

O projeto tem uma grande adesão em relação aos oficineiros, que tendem a se voluntariar novamente após sua primeira participação, o que é considerado pela equipe coordenadora e organizadora como um resultado positivo da ação, já que desperta o interesse crescente na prática extensionista pelos alunos de graduação e na docência. O mesmo acontece em relação às escolas parceiras, que se sentem estimuladas pelo evento nas suas práticas pedagógicas e manifestam o interesse em organizar novas edições. Há ainda a adesão de escolas e caravanas oriundas de outras cidades vizinhas aos locais de realização do Media Day, que participam do evento e posteriormente procuram a equipe manifestando interesse em também poder realizar as atividades em suas sedes.

\section{CONCLUSÃO}

As edições realizadas nas cidades Crateús, Sobral, Fortaleza, Aquiraz e Beberibe se mostraram satisfatória ao atingir os objetivos do projeto e promover esse diálogo com os participantes sobre as novas mídias, proporcionar espaços de letramento e integração, falar sobre o curso de Sistemas e Mídias Digitais e a universidade. O momento acaba abrindo espaço para novas experiências com a parceria escola-pública e universidade, que podem ampliar os horizontes não só dos seus estudantes, mas também de todos que fazem parte das ações: universidade, escola e a comunidade do entorno. Nos debates ocorridos durante o evento é perceptível um impacto positivo acerca das possibilidades de carreira, de vida e perspectivas de futuro dos participantes, que muitas vezes relatam em suas falas o desconhecimento sobre algumas das áreas e temas trabalhados em oficinas ministradas no Media Day.

O público alcançado, como foi mostrado nos resultados, é prioritariamente masculino. Isso é reflexo da desigualdade de gênero que marca a nossa sociedade e acompanha a maioria das áreas englobadas pelo curso. Da mesma forma que é discutido como diminuir essa desigualdade dentro do curso, já se faz necessário repassar esse conhecimento de forma que possa atrair mais pessoas do gênero feminino, considerando que o nosso público também são futuros ingressantes no curso de Sistemas e Mídias Digitais.

Quanto aos oficineiros, nota-se, pelo frequente voluntariado dos que já participaram, que a experiência é produtiva no âmbito do aprofundamento dos conteúdos vistos nas disciplinas, como também pela vivência -muitos pela primeira vez- das práticas docentes, além 
do envolvimento com os integrantes de forma mais amistosa e pessoal. O sentimento nostálgico de retornar para a escola, mesmo não sendo a sua de origem, torna a experiência ainda mais prazerosa para muitos.

Uma vez que o projeto buscar estabelecer pontes concretas entre a universidade e as escolas, aliando os conhecimentos do âmbito acadêmico com as necessidades escolares, a perspectiva que se tem é de que o número e variedade de temas tratados nas oficinas seja sempre crescente. Esse crescimento e multiplicidade tendem a serem estimulados pelas diferentes contribuições possíveis por parte dos oficineiros e palestrantes, pelas gradecurriculares das escolas visitadas e suas estruturas disponíveis. Essa possibilidade de constante renovação e autoavaliação é vista como um fator positivo, pois acaba por alcançar públicos maiores e diferentes interesses, tornando o evento mais diverso e integrador.

Um dos objetivos futuros do projeto está na proposição de edições específicas para professores, haja vista serem cada vez mais necessárias as adoções de metodologias diferenciadas e a integração de meios digitais, o uso de tecnologias na produção de material de ensino, e no âmbito das aulas. Existe ainda o desejo de realizar edições em escolas e cidades diferentes para que a inclusão e o conhecimento possam alcançar mais pessoas e impactar mais lugares e contextos diferentes.

\section{REFERÊNCIAS}

BARRETO, Raquel Goulart. Tecnologia e Educação: trabalho e formação docente. Educação e Sociedade, Campinas, v. 25, n. 89, p.1181-1201, dez. 2004.

BONILLA, Maria Helena. O Brasil e a alfabetização digital. Jornal da Ciência, Rio de Janeiro, p. 7, 13 abr. 2001.

BONILLA, Maria Helena Silveira; PRETTO, Nelson de Luca. Inclusão digital: polêmica contemporânea. 2. ed. Salvador: Edufba, 2011. 188 p. 2 v.

CAVAlCANTE, Andrea Pinheiro Paiva; SILVA, Cátia Luzia Oliveira da. Aulas de campo e as práticas educomunicativas: A sala de aula encontra a realidade. In: CONGRESSO INTERNACIONAL IBERCOM, 14., 2015, São Paulo. Anais... . São Paulo: Assibercom, 2015. v. 1 , p. 1 - 14.

CÉLIO, Emiliano Rostand de Morais; PALMEIRA, Angelina; SILVA, Ricardo Moreira da. Inclusão digital: um desafio para a sociedade. Inclusão Social, Brasília, v. 5, n. 2, p.17-31, jun. 2012.

DEMO, Pedro. Inclusão digital - cada vez mais no centro da inclusão social. Inclusão Social, 
Brasília, v. 1, n. 1, p.36-38, mar. 2005.

DIAS, Lia Ribeiro. Inclusão Digital como fator de Inclusão Social. In: BONILLA, Maria Helena Silveira; PRETTO, Nelson de Luca. Inclusão digital: polêmica contemporânea. 2. ed. Salvador: Edufba, 2011. Cap. 3. p. 61-91.

FREIRE, Paulo. Pedagogia da Autonomia: saberes necessários à prática educativa. 25. ed. São Paulo: Paz e Terra S/a, 1996. 54 p.

MARTINI, Renato. Inclusão Digital \& Inclusão Social. Inclusão Social, Brasília, v. 1, n. 1, p.21-23, mar. 2005.

NASCIMENTO, Maristella Santos et al. Oficinas pedagógicas: construindo estratégias para a ação docente. Saude.com, Bahia, v. 3, n. 1, p.85-95, maio 2007.

PAVIANI, Neires Maria Soldatelli; FONTANA, Niura Maria. Oficinas pedagógicas: relato de uma experiência. Conjectura: Filosofia e Educação, Caxias do Sul, v. 2, n. 14, p.77-88, ago. 2009.

SILVA, R. H. A.; MEIRA, W. Rede de Inclusão e Letramento Digital - Rede. Lê. In: CONGRESSO BRASILEIRO DE EXTENSÃO UNIVERSIT O UNIVERSIT UNIVERSITÁRIA, 2., 2004, Belo Horizonte. Anais eletrônicos... Belo Horizonte: [s.n.], 2004

SILVA, Helena et al. Inclusão digital e educação para a competência informacional: uma questão de ética e cidadania. Ci. Inf., Brasília, v. 34, n. 1, p.28-36, maio 2005.

SILVEIRA, Sérgio Amadeu. "Inclusão Digital, Software Livre e Globalização ContraHegemônica”. In: SILVEIRA, Sérgio Amadeu; CASSINO, João (org.). Software livre e inclusão digital. São Paulo, Editora Conrad Brasil, 2003. 